\title{
A statistical approach for detecting genomic aberrations in heterogeneous tumor samples from single nucleotide polymorphism genotyping data
}

\author{
Christopher Yau ${ }^{1 *}$, Dmitri Mouradov², Robert N Jorissen², Stefano Colella ${ }^{3,6}$, Ghazala Mirza ${ }^{3}$, Graham Steers ${ }^{4}$, \\ Adrian Harris ${ }^{4}$, Jiannis Ragoussis ${ }^{3}$, Oliver Sieber ${ }^{2}$, Christopher $C$ Holmes ${ }^{1,5}$
}

\begin{abstract}
We describe a statistical method for the characterization of genomic aberrations in single nucleotide polymorphism microarray data acquired from cancer genomes. Our approach allows us to model the joint effect of polyploidy, normal DNA contamination and intra-tumour heterogeneity within a single unified Bayesian framework. We demonstrate the efficacy of our method on numerous datasets including laboratory generated mixtures of normalcancer cell lines and real primary tumours.
\end{abstract}

\section{Background}

Single nucleotide polymorphism (SNP) genotyping microarrays provide a relatively low-cost, high-throughput platform for genome-wide pro ling of DNA copy number alterations (CNAs) and loss-of-heterozygosity $(\mathrm{LOH})$ in cancer genomes. These arrays have enabled the discovery of genomic aberrations associated with cancer development or prognosis [1-4] and two recent studies, in particular, have examined 746 cancer cell lines [5] and 26 cancer types [6] revealing much about the landscape of the cancer genome. However, whilst numerous robust computational methods are available for the detection of copy number variants (CNVs) in normal genomes [7-11]; the approaches applied to cancers are often sub-optimal due to data properties that are unique or more pronounced in cancer.

Potential difficulties in the analysis of SNP data from cancers have been considered since the earliest SNP array based cancer studies [12-14] with the principle obstacles being (1) variable tumor purity (normal DNA contamination), (2) intra-tumor genetic heterogeneity, (3) complex patterns of CNA and $\mathrm{LOH}$ events, and (4)

\footnotetext{
* Correspondence: yau@stats.ox.ac.uk

'Department of Statistics, University of Oxford, South Parks Road, Oxford,

OX1 3TG, UK

Full list of author information is available at the end of the article
}

genomic instability leading to aneuploidy/polyploidy. Moreover, these issues are also confounded by previously well-described technical artifacts associated with SNP arrays such as: signal variation due to local sequence content [15] and, complex noise patterns due to variable sample quality and experimental conditions [16].

Dedicated cancer analysis tools that compensate for some of these factors have recently begun to emerge [17-27] but there is currently no single coherent statistical model-based framework that unifies and extends all the principles underlying these many methods. Here, we propose such a framework and illustrate, on a number of different datasets, the improvements in terms of robustness and versatility that can be gained in cancer genome pro ling, particularly in large-sample cancer studies involving the investigation of different molecular sub-types and the use of modern high-resolution SNP arrays (greater than 500,000 markers). Our methods are implemented in a piece of software we call OncoSNP.

\section{Characteristics of SNP data acquired from cancer genomes}

We begin with a brief examination of the characteristics of SNP array data acquired from cancer genomes (for a more thorough review of SNP array analysis and

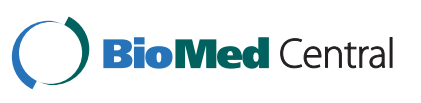

(c) 2010 Yau et al.; licensee BioMed Central Ltd. This is an open access article distributed under the terms of the Creative Commons Attribution License (http://creativecommons.org/licenses/by/2.0), which permits unrestricted use, distribution, and reproduction in any medium, provided the original work is properly cited. 
methodology, see [28-31]). SNP array analysis produces two types of summary measurement for each SNP probe: (i) the Log R Ratio (LRR) which is a measure related to total copy number, analogous to the $\log$ ratio in array comparative genomic hybridization $(\mathrm{aCGH})$ experiments; and (ii) the $\mathrm{B}$ allele frequency (BAF), which measures the relative contribution of the $B$ allele to the total signal (here we use A and B as generic labels to refer to the two alternative SNP alleles). Normalization methods to extract these measurements for the Illumina and Affymetrix SNP genotyping platforms have been previously described $[32,33]$ but is not a subject we treat in detail in this article. In this paper, our examples are based on the Illumina platform and we primarily use the default normalization offered by Illumina's proprietary BeadStudio/GenomeStudio software or the tQN normalization [33] where appropriate. However, the methods described are not intrinsically tied to the Illumina platform and we are actively working to transfer these techniques for use with the Affymetrix platform.

Figure 1 (top panel) depicts data for chromosome 1 of a breast cancer cell line (HCC1395, ATCC CRL-2324) and a EBV transformed lymphoblastoid cell line (HCC1395BL, ATCC CRL-2325) derived from the same patient from a previously published dataset [24]. Downward shifts in the Log R Ratios indicate DNA copy

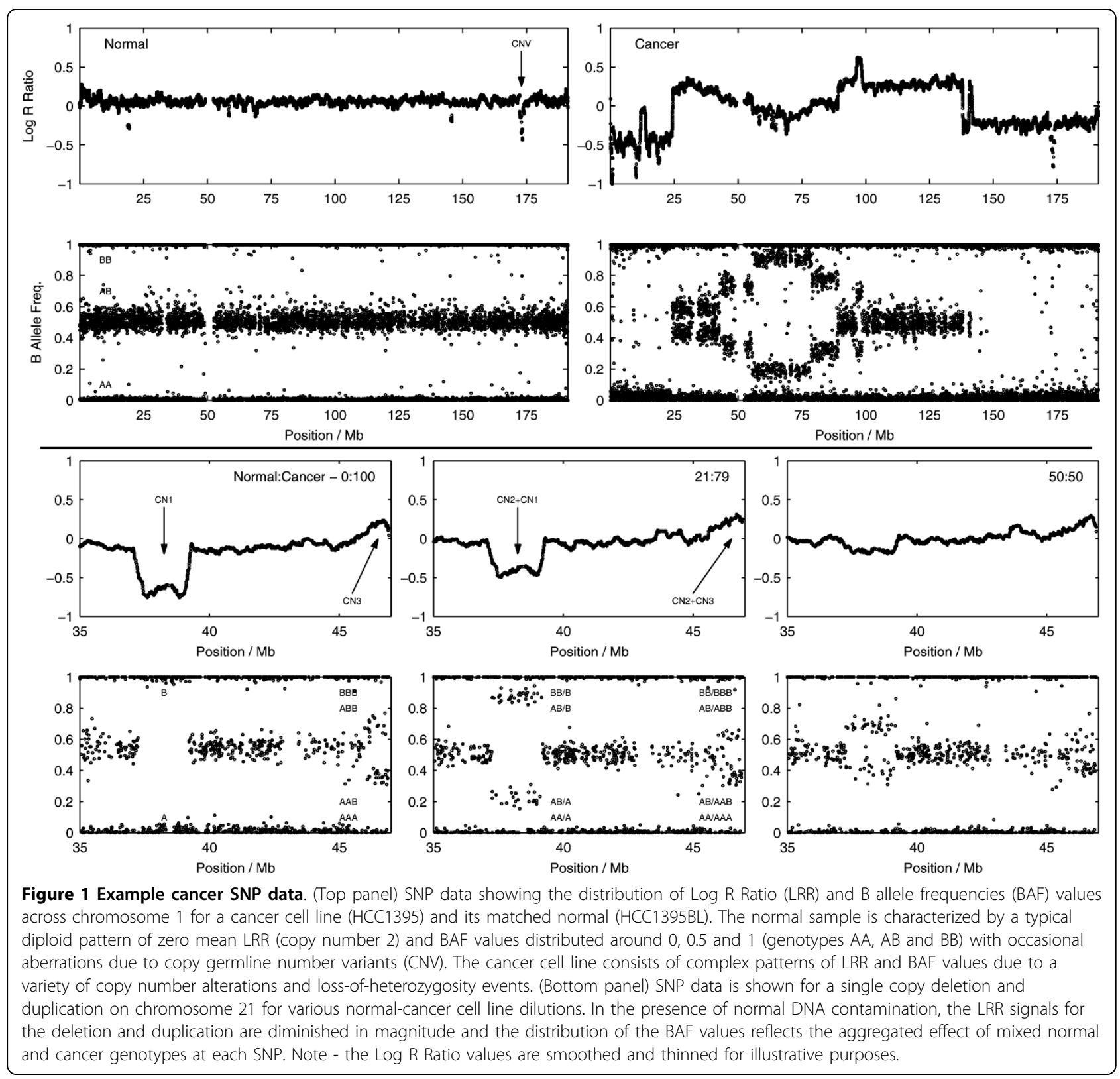


number losses relative to overall genome dosage, whilst copy number gains cause upward shifts. The BAF tracks changes in the relative fractions of the $B$ allele due to CNA and/or LOH.

In the non-cancer (normal) lymphoblastoid cell line, the LRRs are distributed around zero corresponding to DNA copy number 2; whilst the BAFs are clustered around values of $0,0.5$ and 1 that correspond to the diploid genotypes AA, AB and BB. Small aberrations in the normal data can be observed due to germ line CNVs but the genome is otherwise stable. The cancer cell line presents a much more complex scenario with extensive genomic rearrangements leading to considerable variation in the SNP data. This is not an atypical scenario for cancers which often feature large numbers of focal aberrations and whole or partial chromosomal copy number changes although this can vary considerably depending on the cancer type and the stage of the disease. The question we address here is: how do we translate this SNP data into actual copy number and LOH calls?

\section{Effects of polyploidy}

One distinctive difference between the normal and cancer datasets is that the LRR values are not directly comparable. Experimental protocols for SNP arrays constrain the amount of DNA, not the number of cells, to be the same for each sample assayed. For example, a purely metalloid genome containing no other chromosomal alterations could not be distinguished from a diploid genome, as the same mass of genomic material would be hybridized on to the SNP array. The situation is further compounded by standard normalization methods that transform the probe intensity data on to a common reference scale or "virtual diploid state" [34] in order to correct for between-array or cross-sample variability.

The result is that the (zero) baseline of the LRR for the cancer cell line or tumor sample does not correspond to a normal diploid copy number but to the average copy number (ploidy) of the sample. In order to determine absolute copy number values, a correct baseline for the interpretation of the LRR values must be determined but this is a challenging problem since, for any particular cancer sample, the ploidy is generally unknown a priori, maybe a fractional value and varies from one cancer to the next. Methods to tackle baseline uncertainty for polyploid tumors have recently been developed $[17,21]$ but these are only effective in the absence of normal DNA contamination and intratumor heterogeneity making them most effective for use with cancer cell lines and very high purity tumor samples.

\section{Normal contamination and intra-tumor heterogeneity}

Normal DNA contamination can also be a significant barrier to the correct interpretation of SNP data as illustrated in Figure 1 (bottom panel). The SNP data shown comes from various artificial mixtures of the cancer cell line and paired normal cell line [33] for a single-copy deletion and duplication on chromosome 21. The SNP array measures both the contribution of the normal and tumor genotypes hence, the $B$ allele frequencies for the deletion and duplication appear as four bands, reflecting the mixed normal-tumour genotypes $\mathrm{AA} / \mathrm{A}, \mathrm{AB} / \mathrm{A}, \mathrm{AB} /$ $\mathrm{B}$ or $\mathrm{BB} / \mathrm{B}$ for the single-copy deletion and $\mathrm{AA} / \mathrm{AAA}$, $\mathrm{AB} / \mathrm{AAA}, \mathrm{AB} / \mathrm{BBB}$ or $\mathrm{BB} / \mathrm{BBB}$ for the single-copy duplication. Moreover, as the normal DNA content increases, the magnitude of the shifts in the LRR values associated with the deletion and duplication are reduced.

It is of interest to note that whilst the presence of normal DNA affects SNP data globally, localized variation can also exist due to intra-tumor heterogeneity and aggregation from multiple co-existing cancer cell clones each harboring their own distinct pattern of genomic aberrations. These mixed signals must be deconvolved in order to ascertain the underlying somatic changes and a number of methods [20,22,24-27] have been proposed to tackle the issue of normal DNA contamination. These approaches often assumed the absence of the effects of polyploidy described previously and therefore are principally suited to the analysis of normal DNA contaminated and near-diploid tumor samples.

\section{Results and Discussion Model overview}

The development of our method, implemented in OncoSNP, has been motivated by the need to address both the effects of normal DNA contamination and polyploidy simultaneously. Normal tissue contaminated polyploid tumors are frequently observed in studies of, for example, colon or breast cancers and, at the time of writing, only one method Genome Alteration Print [23], based on pattern recognition heuristics, has been developed to manage both these highly important issues in SNP array based cancer analysis. Our approach differs from previous methods in that it attempts to tackle the issues of normal DNA contamination, intra-tumor heterogeneity and baseline ploidy normalization artifacts jointly within a coherent statistical framework. The model assumes that, at each SNP, each tumor cell of a given specimen either retains the normal constitutional genotype or possesses an alternative but, common, tumor genotype. However, in contrast to other methods, we explicitly parameterize the proportion of cells that possess the normal genotype at each SNP. This proportion is determined by a genome-wide fraction attributed 
to normal DNA contamination and the proportion of tumor cells that have remained unchanged at that SNP which is allowed to vary along the genome thus allowing for intra-tumor heterogeneity (the underlying statistical model is illustrated in Figure 2). We also include a LRR baseline adjustment parameter that allows inference of the unknown tumor ploidy in a statistically rigorous manner.

Bayesian methodology is applied to impute the unknown normal-tumor genotypes, the normal genotype proportion and to assign a probabilistic score of each SNP belonging to one of twenty-one different "tumor states" (Table 1). Experimental noise is accounted for using a flexible semi-parametric noise (mixture of Student $t$-distributions) model that is able to adaptively fit complex noise distributions to the SNP data, and our method further adjusts for wave-like artifacts correlated to local GC content [35].

Our MATLAB implementation typically requires between 0.5-3 hours processing per sample dataset (containing approximately 600,000 probes) depending on the run-time options specified. A variety of user settings are provided to allow the performance of the method to be tuned to the particular application and longer processing times are required where little prior information is provided and the method is required to learn all characteristics directly from data. As the method analyzes each sample independently, parallel processing of multiple samples simultaneously is trivially implemented.

\section{Polyploidy correction}

In order to demonstrate the ability of OncoSNP to correctly adjust the baseline for the Log $\mathrm{R}$ Ratio to the actual baseline for aneuploid/polyploid samples, we analyzed SNP data for ten well-characterized cancer cell lines (Table 2). Karyotype information for each cell line were retrieved from the online database for the American Type Culture Collection (ATCC) or previous karyotype studies [36,37].

Figure 3(a-c) shows examples of the baseline adjustment for three cancer cell lines focusing on selected chromosomes. In each case, OncoSNP adjusts the baseline to center on the regions of allelic balance (BAFs equal to 0.5 ) corresponding to copy number 2 enabling the correct absolute copy number values to be determined. Note that it is the allele-specific information in the $\mathrm{B}$ allele frequencies that inform us of the baseline error, and variation in the intensity-based LRR does not yield this information on its own.

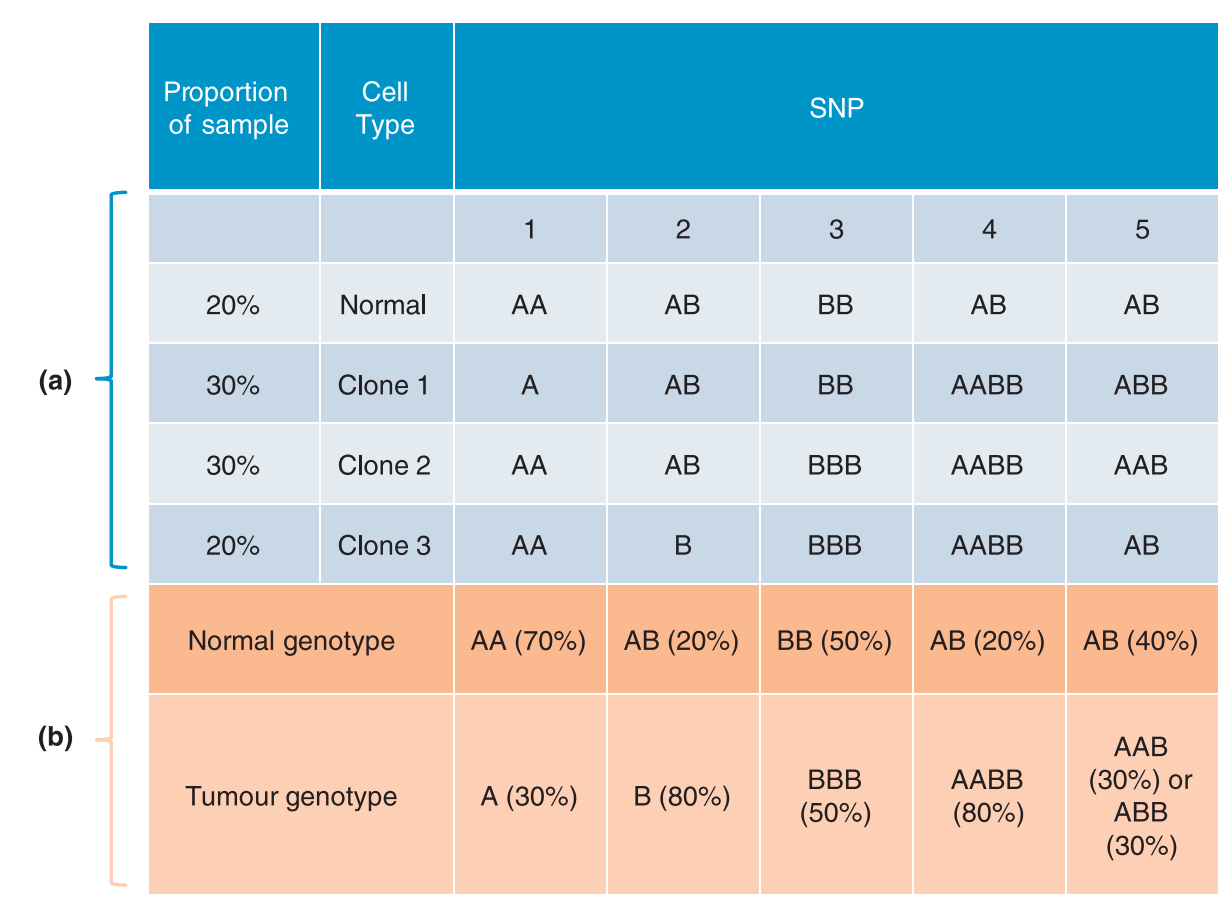

Figure 2 Illustrating the statistical model. (a) The tumor sample consists of DNA contributions from an unknown number of clones (here, we illustrate three clones) and normal cells in different proportions. Each clone has its own set of tumor genotypes which are derived from the normal genotypes by the loss or duplication of alleles. (b) Our statistical model assumes that, at each locus, there exists a normal and a common tumor genotype. OncoSNP estimates the normal and common tumor genotype and the proportion of the sample explained by each genotype from the SNP data. The situation depicted at SNP 5 involves clones with different tumor genotypes - this is not considered under our model. 
Table 1 OncoSNP tumor states

\begin{tabular}{|c|c|c|c|}
\hline \multicolumn{4}{|c|}{ Tumor states } \\
\hline Tumor state & Tumor copy number & Allowable tumor-normal genotypes & Description \\
\hline 1 & 0 & $(-, A A),(-, A B),(-, B B)$ & Homozygous deletion \\
\hline 2 & 1 & $(A, A A),(A, A B),(B, A B),(B, B B)$ & Hemizygous deletion \\
\hline 3 & 2 & $(A A A A, A A),(A A A B, A B),(A B B B, A B),(B B B B, B B)$ & Normal \\
\hline 4 & 3 & $(A A A, A A),(A A B, A B),(A B B, A B),(B B B, B B)$ & Single copy duplication \\
\hline 5 & 4 & $(A A A A, A A),(A A A B, A B),(A B B B, A B),(B B B B, B B)$ & 4n monoallelic amplification \\
\hline 6 & 4 & $(A A A A, A A),(A A B B, A B),(B B B B, B B)$ & 4n balanced amplification \\
\hline 7 & 5 & $(A A A A A, A A),(A A A A B, A B),(A B B B B, A B),(B B B B B, B B)$ & 5n monoallelic amplification \\
\hline 8 & 5 & $(A A A A A, A A),(A A A B B, A B),(A A B B B, A B),(B B B B B, B B)$ & 5n unbalanced amplification \\
\hline 9 & 6 & $(\mathrm{AAAAAA}, \mathrm{AA}),(\mathrm{AAAAAB}, \mathrm{AB}),(\mathrm{ABBBBB}, \mathrm{AB}),(\mathrm{BBBBBB}, \mathrm{BB})$ & 6n unbalanced amplification \\
\hline 10 & 6 & $(\mathrm{AAAAAA}, \mathrm{AA}),(\mathrm{AAAABB}, \mathrm{AB}),(\mathrm{AABBBB}, \mathrm{AB}),(\mathrm{BBBBB}, \mathrm{BB})$ & 6n unbalanced amplification \\
\hline 11 & 6 & $(\mathrm{AAAAAA}, \mathrm{AA}),(\mathrm{AAABBB}, \mathrm{AB}),(\mathrm{BBBBB}, \mathrm{BB})$ & 6n unbalanced amplification \\
\hline 12 & 2 & $(A A, A A),(A A, A B),(B B, A B),(B B, B B)$ & 2n somatic $\mathrm{LOH}$ \\
\hline 13 & 3 & $(A A A, A A),(A A A, A B),(B B B, A B),(B B B, B B)$ & 3n somatic $\mathrm{LOH}$ \\
\hline 14 & 4 & $(A A A A, A A),(A A A A, A B),(B B B B, A B),(B B B B, B B)$ & 4n somatic $\mathrm{LOH}$ \\
\hline 15 & 5 & $(\mathrm{AAAAA}, \mathrm{AA}),(\mathrm{AAAAA}, \mathrm{AB}),(\mathrm{BBBBB}, \mathrm{AB}),(\mathrm{BBBBB}, \mathrm{BB})$ & 5n somatic $\mathrm{LOH}$ \\
\hline 16 & 6 & $(\mathrm{AAAAAA}, \mathrm{AA}),(\mathrm{AAAAAA}, \mathrm{AB}),(\mathrm{BBBBBB}, \mathrm{AB}),(\mathrm{BBBBBB}, \mathrm{BB})$ & 6n somatic $\mathrm{LOH}$ \\
\hline 17 & 2 & $(A A, A A),(B B, B B)$ & 2n germline $\mathrm{LOH}$ \\
\hline 18 & 2 & $(\mathrm{AAA}, \mathrm{AA}),(\mathrm{BBB}, \mathrm{BB})$ & 3n germline $\mathrm{LOH}$ \\
\hline 19 & 2 & $(\mathrm{AAAA}, \mathrm{AA}),(\mathrm{BBBB}, \mathrm{BB})$ & 4n germline $\mathrm{LOH}$ \\
\hline 20 & 2 & $(\mathrm{AAAAA}, \mathrm{AA}),(\mathrm{BBBBB}, \mathrm{BB})$ & 5n germline $\mathrm{LOH}$ \\
\hline 21 & 2 & $(\mathrm{AAAAAA}, \mathrm{AA}),(\mathrm{BBBBBB}, \mathrm{BB})$ & 6n germline $\mathrm{LOH}$ \\
\hline
\end{tabular}

Description of the 21 tumor states showing corresponding copy numbers and genotypes. OncoSNP assigns a score of each SNP being in each of the twenty-one tumor states.

Overall, Figure 3d shows that a strong linear relationship exists with near-diploid cell lines (SW837 and HL60) requiring less baseline adjustment compared to polyploid cell lines. This behavior is encouraging since we might expect the degree of baseline adjustment required to scale linearly with chromosome number. As a result, OncoSNP was able to correctly estimate the chromosome number for each cancer cell line.

Table 2 Cancer cell lines

\begin{tabular}{ccc}
\hline \multicolumn{3}{c}{ Cancer cell lines } \\
\hline Cell line & $\begin{array}{c}\text { Chromosome number } \\
\text { (modal, range) }\end{array}$ & Reference \\
\hline HL60 & $46(44-46)$ & Liang et al. (1999) \\
HT29 & $70(69-73)$ & Adbel-Rahman et al. (2000) \\
SW1417 & $70(66-71)$ & Adbel-Rahman et al. (2000) \\
SW403 & $64(60-65)$ & Adbel-Rahman et al. (2000) \\
SW480 & $58(52-59)$ & Adbel-Rahman et al. (2000) \\
SW620 & $48(45-49)$ & Adbel-Rahman et al. (2000) \\
SW837 & $38(38-40)$ & Adbel-Rahman et al. (2000) \\
LIM1863 & $80(66-82)$ & Adbel-Rahman et al. (2000) \\
MDA-MB- & $84(82-89)$ & ATCC \\
175 & & ATCC \\
MDA-MB- & $64(60-67)$ & \\
468 & & \\
\hline
\end{tabular}

A list of cancer cell lines analyzed and estimates of their chromosome number retrieved from the literature.

\section{Analysis of normal-cancer cell line mixtures}

We applied OncoSNP to three datasets each containing mixtures of normal and cancer cell line DNA. SNP data was also generated in-house for 0:100, 25:75 and 50:50 normal-cancer cell lines mixtures (mixing ratios by mass) for a hypo-diploid (SW837) and triploid (SW403) colon cancer cell line. As paired normal cell lines were not available for these cancer cell lines, we used an nonpaired normal DNA sample and filtered out non-compatible SNPs (the filtering method is described in detail in Supplementary methods in Additional file 1) to generate pseudo-paired normal-cancer cell line mixtures. We also analyzed the 0:100, 21:79 and 50:50 mixtures of the HCC1395/HCC1395BL matched normal-cancer cell lines from [24].

Figure 4 shows results from an analysis of chromosome 1 of the mixture series for SW837. OncoSNP identifies the p-arm deletion successfully in all the samples even as the level of normal contamination increases. GenoCN and Genome Alteration Print (GAP) show less robustness particularly at the higher normal contamination level and, in the case of GAP for the 25:75 mixture, it incorrectly predicts that the sample is tetraploid. Additional plots for all three cell line mixtures are given in Additional file 2. Figure 5 shows that overall, OncoSNP estimates of chromosome number, copy 


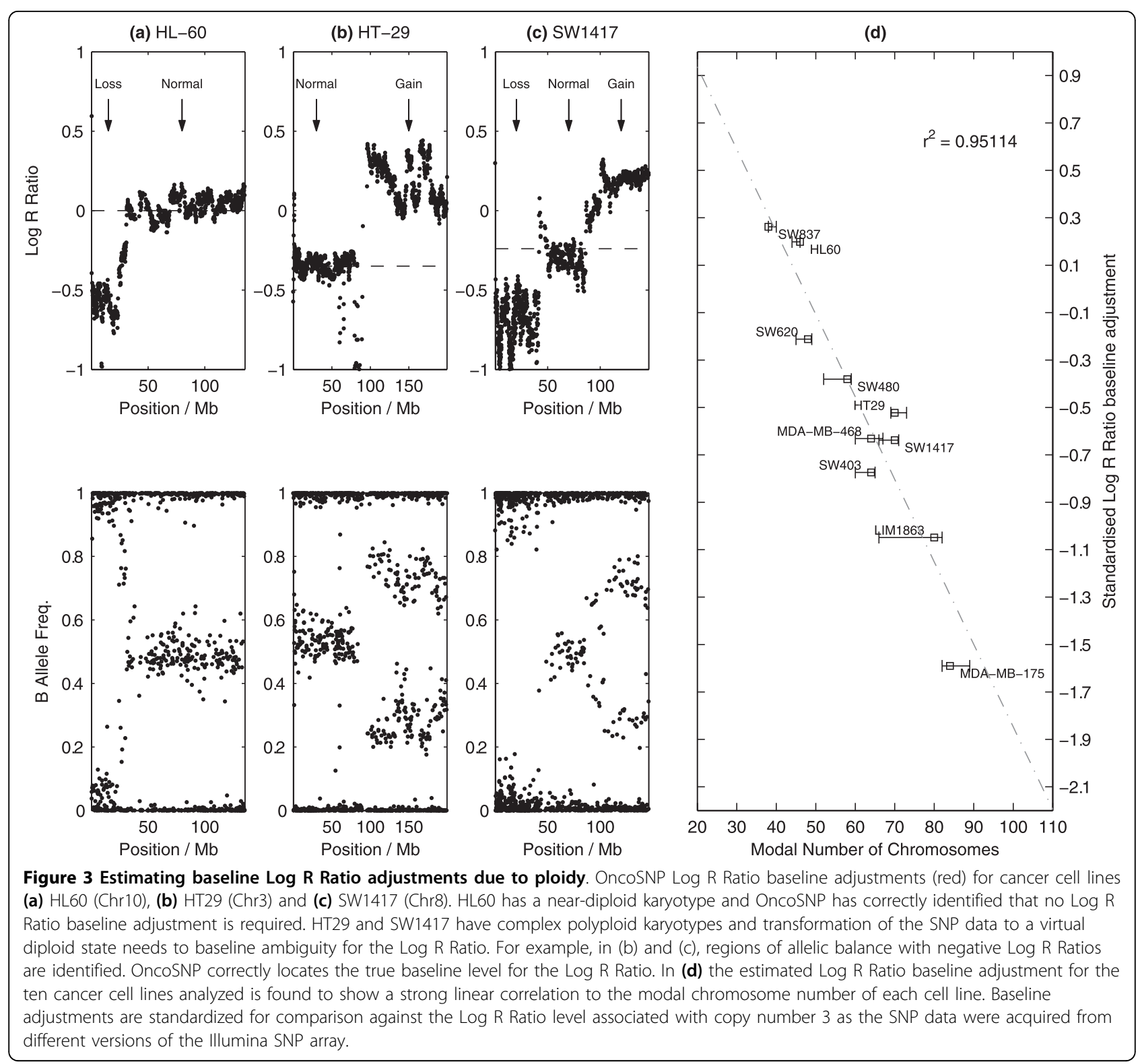

number and $\mathrm{LOH}$ from the mixtures remained highly self-consistent even with the addition of the normal DNA and were more robust than the other methods tested. For the colon cancer cell lines, the chromosome numbers predicted by OncoSNP (40 and 64 for SW837 and SW403 respectively) matched known karyotype information (SW837, range 38-40; SW402, range 60 to 65) [36].

Whilst it should be stressed that careful sample preparation should keep normal contamination to a minimum in many real studies of primary tumors, the reliability of OncoSNP, up to 50\% tumor purity, is nonetheless reassuring as clinical estimates of tumor purity can be inconsistent with observed genotyping data [25].

\section{Model comparison}

In order to demonstrate the utility of integrating both normal DNA contamination and LRR baseline correction within a single analysis model; we examined SNP data acquired from laboratory generated normal-cancer cell lines mixtures to simulate normal contamination of tumor samples.

The data was analyzed using four variants of our model: a germline model, in which we assume no baseline adjustment is required and no normal DNA contamination exists; a ploidy-only model, in which we perform baseline adjustment only; a normal contamination-only model, where we allow for normal DNA contamination but no baseline adjustment and our full, 


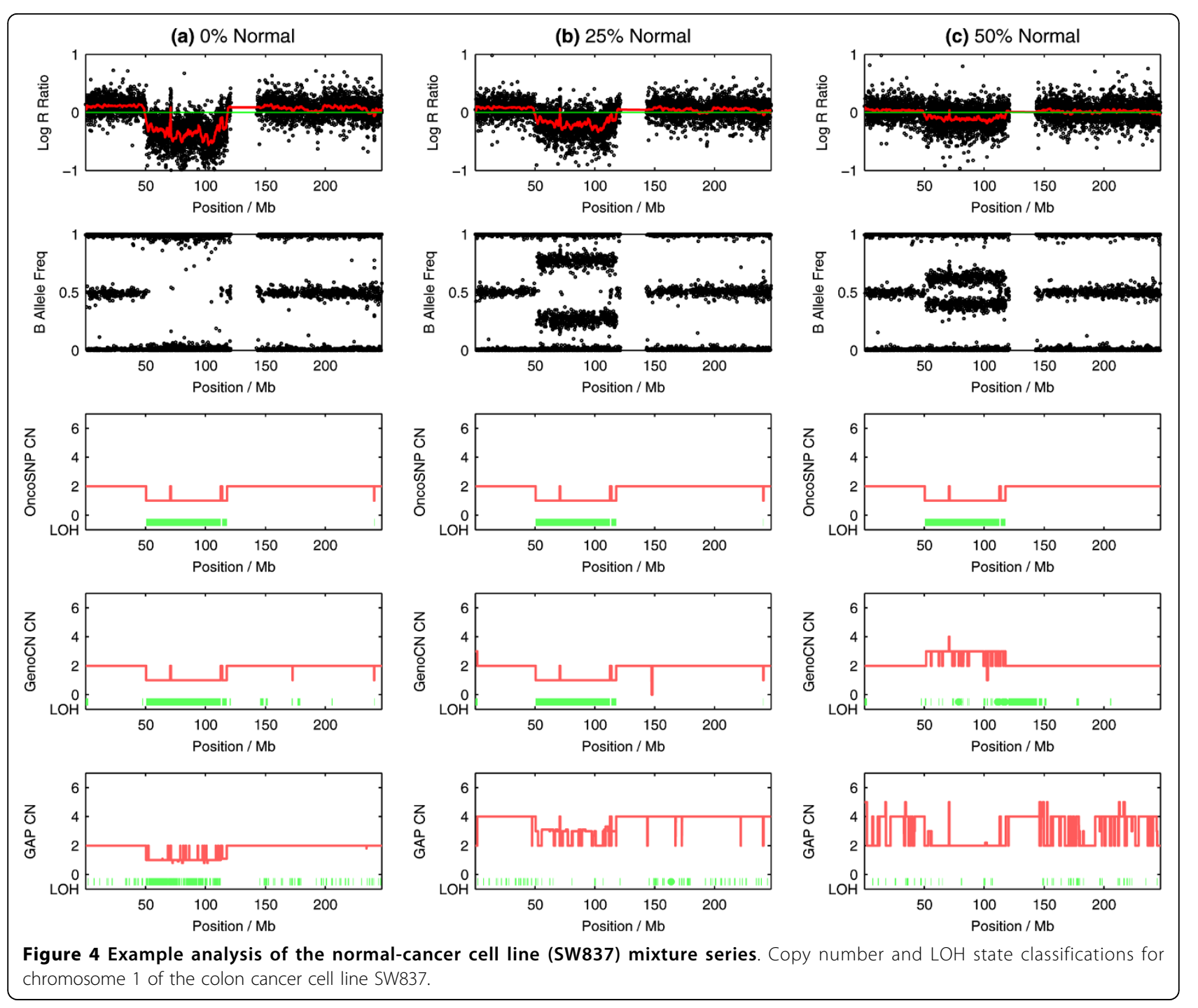

integrated OncoSNP model. It should be noted that all the model variants we consider are nested within the full model; and are obtained by either fixing parameters or specifying strict prior probability distributions.

Figure 6 shows genome-wide copy number profiles attained from the four variants of our model on the cell line mixtures. The analysis of the hypo-diploid cell line SW837 mixtures showed that the germline- and ploidyonly models, which do not take into account normal DNA contamination, produced substantially different profiles as the level of normal DNA contamination was altered. Only the normal- and full OncoSNP models were capable of reproducing genome-wide copy number profiles consistently with minimal discrepancy.

The analysis of the triploid SW403 cell line mixture series highlights the particular strengths of our model. The correct interpretation of the SNP data requires consideration of the underlying triploid nature of the cancer cell line and the varying levels of normal DNA contamination. As the germline-, normal- and ploidy-only models are only able to compensate for only one of these factors but not both, there are discrepancies in the genome-wide profiles between samples. In contrast, the full OncoSNP model reproduces genome-wide copy number profiles for each mixture sample with relatively greater consistency. These results motivate the utility of inferring both baseline ploidy and normal contamination within an integrated framework since the ploidy status and tumor purity of actual clinical cancer samples are often unknown.

\section{Microdissected tumor samples}

We validated our approach to determine stromal contamination in an experimental setting by studying SNP data for three primary breast tumors (Cases 114, 601 and 3,364$)$. For each case, we analyzed data acquired 


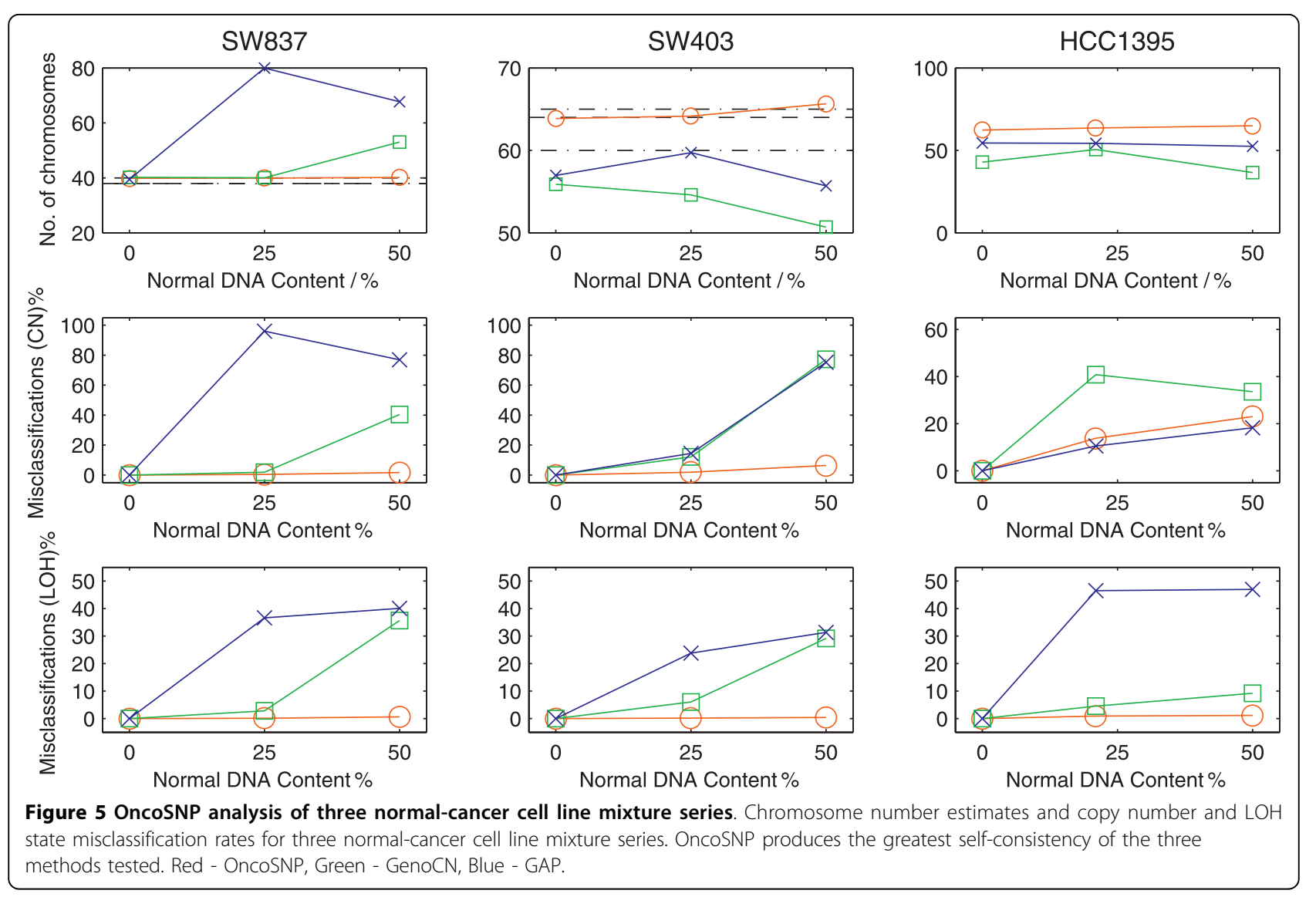

from microdissected and non-dissected tumor material such that, in an ideal scenario, predicted copy number and $\mathrm{LOH}$ profiles obtained from the two samples should be identical. Visual inspection of the SNP data suggests that all three tumors are triploid and a baseline Log $\mathrm{R}$ Ratio adjustment is required. Genome-wide copy number profiles for each material type and case are shown in Figure 7 (more detailed plots are given in Additional file 3). Qualitatively, the genome-wide copy number profiles produced by OncoSNP show the least discrepancy compared to the other methods tested. It should be noted that visual inspection of the SNP data for the non-dissected material for cases 601 and 3,364 suggested that they were highly contaminated by stromal tissue and were reinforced by normal DNA content estimates of $70 \%$ and $60 \%$ by OncoSNP, compared to $30 \%$ and $20 \%$ in the microdissected material. The ability of OncoSNP to recover so many gross profile features despite this level of stromal contamination demonstrates its ability to be robust in even the most extreme circumstances. For case 114, the non-dissected and microdissected material were estimated to contain $30 \%$ and $10 \%$ normal contamination.

Quantitatively, the proportion of SNPs showing copy number classification discrepancies between the microdissected and non-dissected sample analysis were 7.6\%, $21.9 \%$ and $19.3 \%$ for cases 114,601 and 3,364 respectively. This is compared to $6.4 \%, 52.1 \%$ and $27.0 \%$ with GenoCN and $8.5 \%, 86.2 \%$ and $99.0 \%$ with GAP. Note that whilst GenoCN showed strong reproducibility for case 114, it misclassified the ploidy in both instances as its operation is limited to diploid tumors.

\section{Statistical uncertainty}

A feature of our statistical framework is the ability to highlight and explore ambiguity in the interpretation of SNP data from contaminated polyploid tumor samples. Figure 8 shows a likelihood contour plot derived from a cancer sample whose ploidy status and normal DNA content are unknown. The likelihood plot gives the probability of the SNP data associated with different possibilities for the normal DNA content and LRR baseline adjustments. In this example, the likelihood possesses three modes each corresponding to a different, but compatible, biological interpretation of the data. The likelihood associated with each of the three modes is very similar and in the absence of external karyotype information, or prior knowledge of the tumor ploidy or the level of normal DNA contamination, each of these interpretations is entirely plausible. 


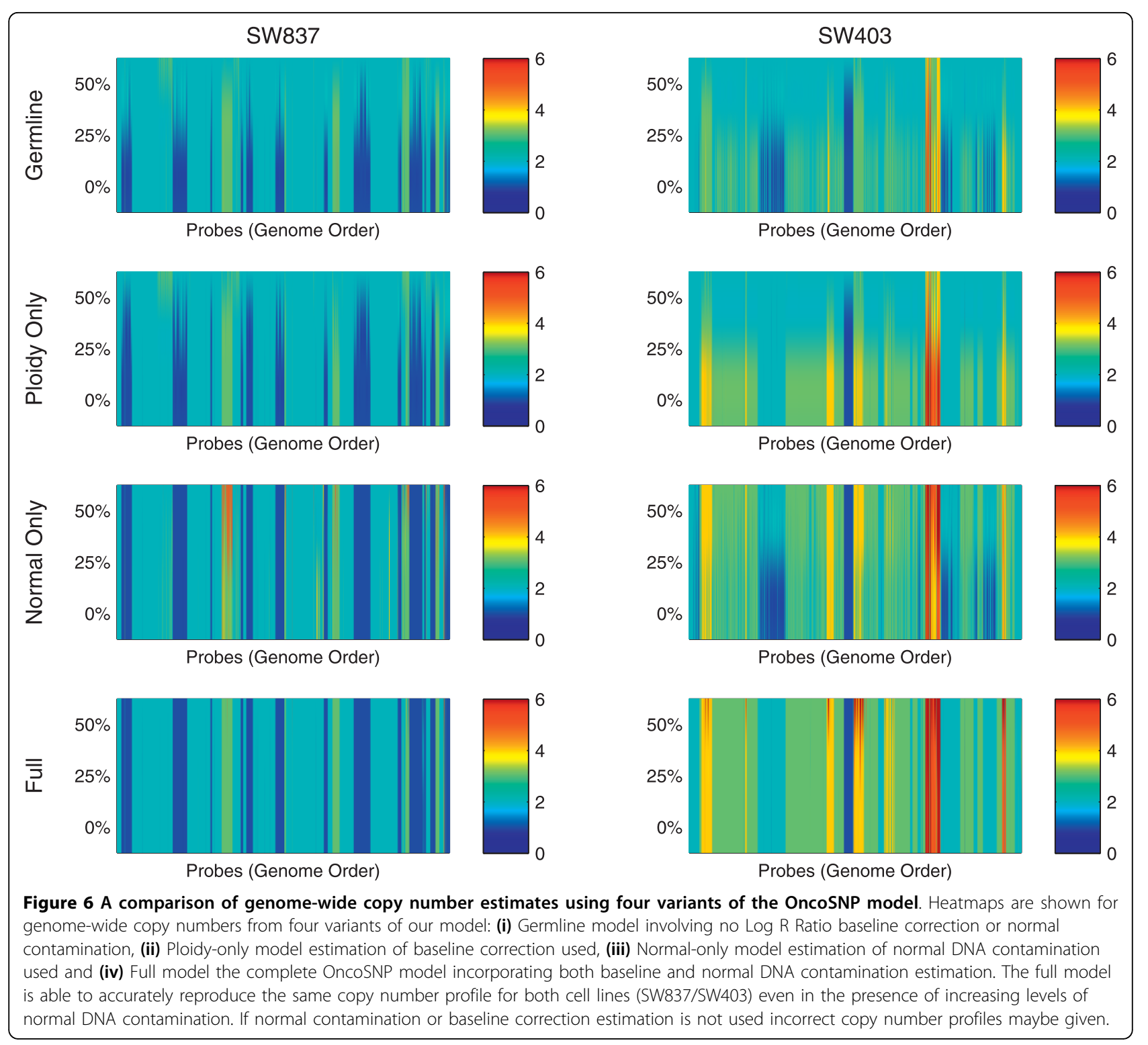

Our statistical model allows us to explore this twodimensional parameter space enabling each of these data interpretations to be considered in a statistically rigorous manner. In contrast, methods that restrict themselves to consideration of normal DNA contamination or baseline adjustment only will only have access to particular one-dimensional planes which may lead to alternative interpretations of the SNP data being missed. Although we anticipate that many cancers should exhibit a sufficient level of genomic alteration to make the data informative about tumor ploidy and purity, a consideration of alternate ploidy-purity levels maybe an important factor in the characterization of particular cancer sub-types that may not exhibit complex changes.

\section{Conclusions}

The development of our method has been motivated by an on-going genome-wide study of one-thousand paired normal-colorectal cancers. The pro ling of genomic aberrations in these cancers is an important step in identifying genetic abnormalities involved in disease initiation and progression as well as patterns of somatically-acquired alterations associated with particular clinical phenotypes and therapeutic response. The genomic features of colorectal cancer form a particularly useful platform for methods development since colon tumor samples frequently contain normal DNA contamination and there exist at least two well-characterized molecular sub-types: the microsatellite-stable (MSS) and microsatellite-unstable (MSI) groups. MSI colon cancers are 


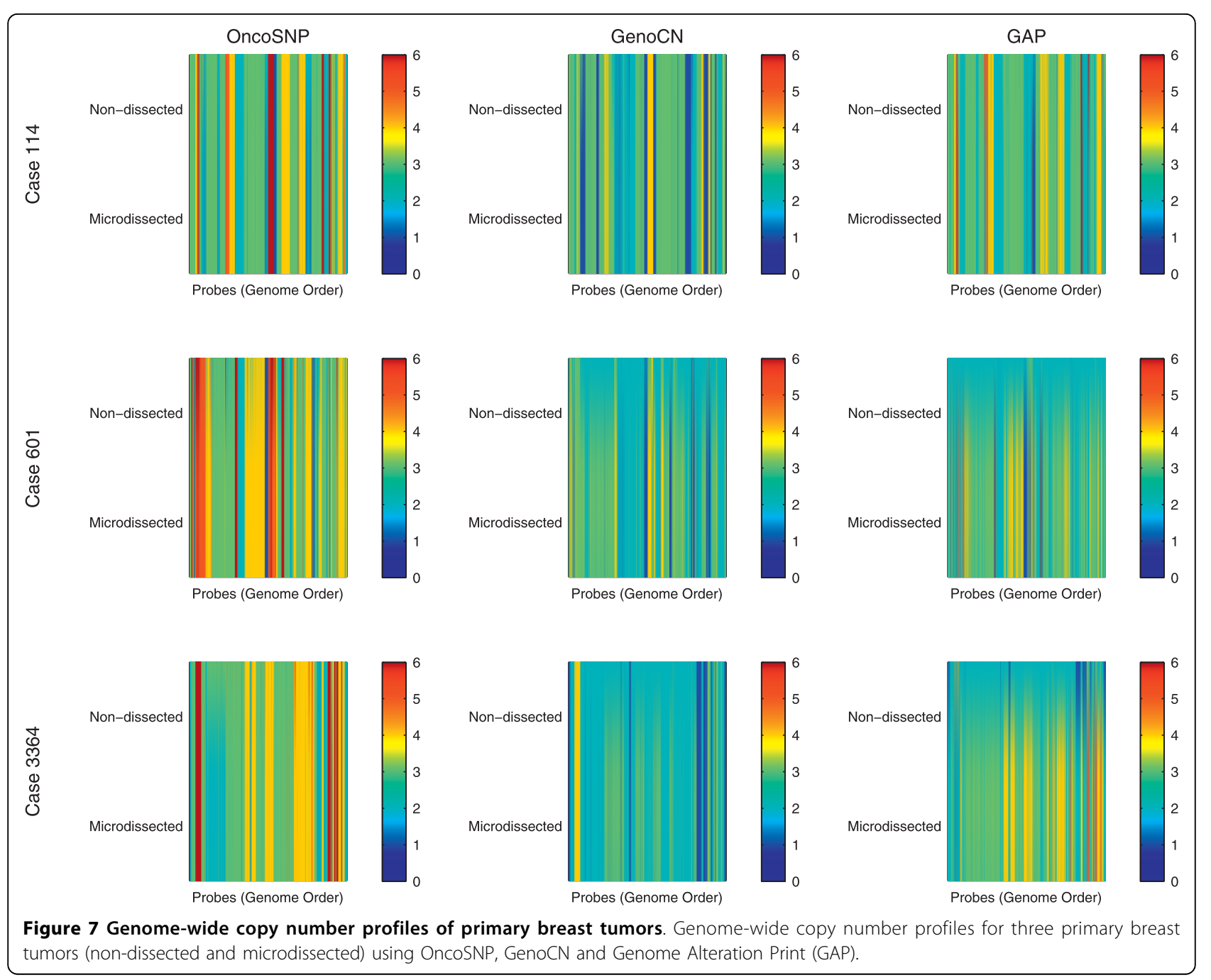

associated with a near-diploid karyotype, with comparatively few structural rearrangements; whilst MSS colon cancers are characterized by extensive structural rearrangements and frequently exhibit a triploid or tetraploid karyotype [38]. As our approach considers the combined effects of ploidy changes and tumor heterogeneity jointly within an integrated statistical framework, we have been able to highly automate the process of analyzing SNP data from a large cohort of colon cancers and robustly operate over a range of scenarios posed by each of the molecular sub-types.

Fundamental to the success of our approach is the rigorous exploitation of allele-specific information for estimating normal DNA contamination and tumor ploidy. Historically, one of the key advantages of SNP arrays over aCGH technologies has been the availability of allele-specific information to allow the detection of $\mathrm{LOH}$ events. In our method, we have utilized this second axis of information to determine absolute copy number and predict tumor purity that would be challenging to implement with the one-dimensional datasets produced by aCGH alone.

Recently, next generation sequencing (NGS) technologies have proven to be a powerful new force in the toolkit of cancer geneticists allowing cancer genomes to be probe at greater resolutions and more levels of detail than ever before [39-42]. Nonetheless, SNP arrays are likely to remain a useful analysis tool in cancer studies for the foreseeable future as SNP arrays remain more cost- and resource-effective as a means of sampling large numbers of tumors. In addition, as short-read sequencing technologies are not immune to many of the issues that we have discussed. For instance, [42] used pathology review to estimate tumour cellularity in their primary tumour and the brain metastasis and xenograft samples and adjusted sequence read counts accordingly. The integration and reconciliation of SNP data with libraries of short-read sequence data would allow more 


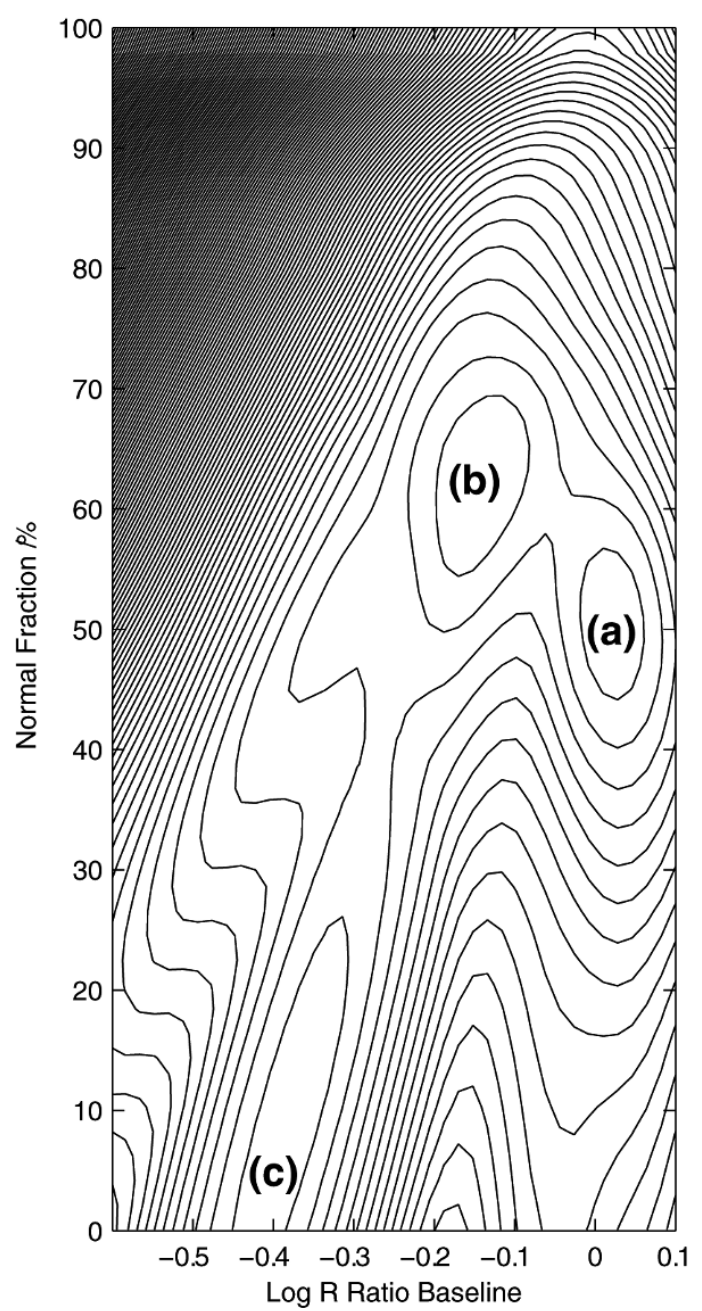

(a)
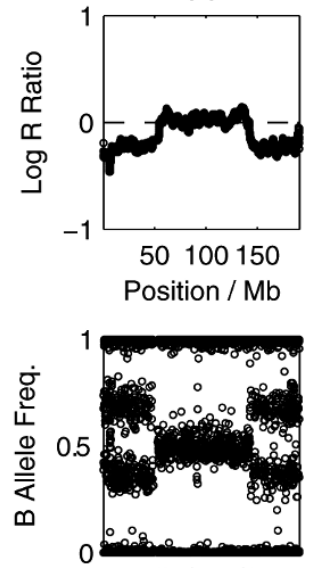

50100150

Position / Mb
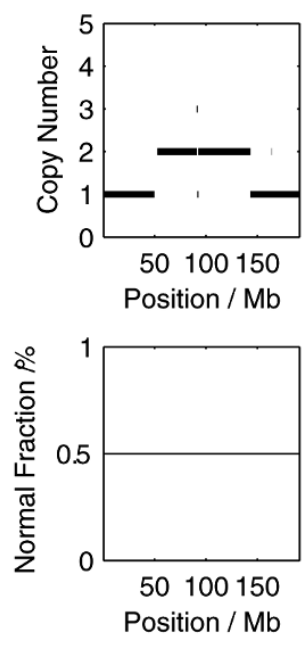

(b)
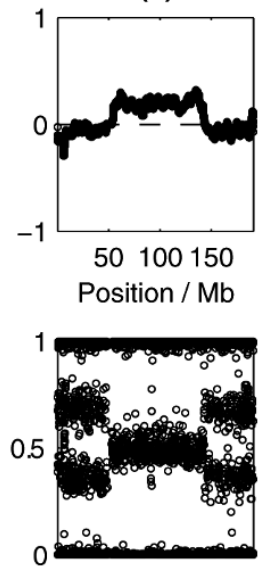

50100150

Position / Mb
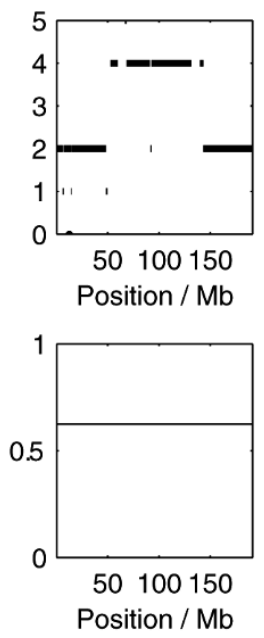

(c)
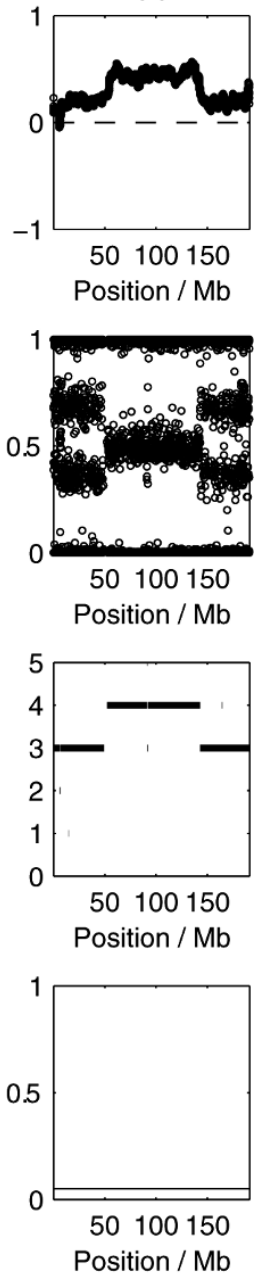

Figure 8 Analysis of a tumor sample with an unknown ploidy status and normal DNA contamination. A likelihood contour plot shows that there are three modes each corresponding to an alternative explanation of the SNP data: (a) the tumor has near-diploid karyotype and contaminated with 50\% normal DNA content, (b) the tumor has a tetraploid karyotype with 60\% normal DNA content and (c) the tumor has a near-triploid karyotype with negligible normal DNA content. The maximum log-likelihood at each mode is very similar.

accurate determination of normal DNA contamination and allow the use of SNP data as a sca old upon which to reconstruct the more detailed and low-level cancer sequence data. It may also be possible to adapt the methods presented here for use for short read sequencing platforms. One possible approach is to model the allele-specific read counts at known SNP locations directly and modify the emission distribution in the Hidden Markov model from a continuous to a discrete distribution (for example Poisson or Negative-Binomial). Alternatively, the existing data model can be maintained and the read counts transformed into near-continuous measures with the Log $\mathrm{R}$ Ratio represented as the log ratio of the total read depth and a (local) normalizing constant derived from, say, a matched germline sample and the B Allele Frequency calculated from the ratio of the number of reads containing the $\mathrm{B}$ allele to total read depth. However, we would advise that any attempts to implement these techniques for application to sequencing technologies should be supported by extensive control and calibration experiments of the type described in this paper and by previous works.

In conclusion, we have described a novel computational tool (OncoSNP) for genomic copy number and $\mathrm{LOH}$ pro ling of heterogeneous tumors using SNP arrays. Using formal statistical modeling we are able to jointly consider a number of complex factors arising in SNP array-based tumor analysis. In a number of experiments, we demonstrated the ability of our method to give consistent results in the presence of both tumor heterogeneity and unknown baseline ploidy using both cancer cell lines and clinical samples. We believe that 
our method could substantially improve the analysis of tumor SNP data particularly in large studies of clinical samples where there may be exist considerable variation in the underlying genetics as well as factors such as tumor purity and sample quality.

\section{Materials and methods \\ Materials \\ Dilution series}

Illumina HumanCNV370-Duo BeadChip Infinium SNP data for dilution series of 12 mixtures of cancer cell line (HCC1395) mixed with its paired normal cell line (HCC1395BL) were downloaded from the NCBI Gene Expression Omnibus accession [GEO:GSE11976]. We excluded chromosome 6 and 16 from analysis due to copy genomic aberrations present in the normal cell line HCC1395BL.

\section{Cancer cell lines}

Illumina HumanHap300 data for the promyelocytic leukemia cancer cell HL-60 and colon cancer cell line HT-29 were obtained from Illumina, and Human-610 Quad SNP genotyping data for the colon cancer cell lines SW403, SW480, SW620, SW837, SW1417 and LIM1863 were generated at the Ludwig Institute of Cancer Research using standard processing protocols. The genotyping data for breast cancer cell lines MDA-175 and MDA-468 were downloaded from the NCBI Gene Expression Omnibus accession [GEO:GSE18799] [23].

\section{Primary breast tumors}

Three breast tumors (cases 114, 601 and 3,364) that had not received non-neoadjuvant therapy were analyzed in detail using material derived from microdissection. For each case, material containing pure tumor and pure stroma cells respectively was microdissected and compared to data obtained from surgically obtained material from the same tumors. Case 114 was of Luminal B type (23 mm tumor, moderately differentiated infiltrating ductal carcinoma with an extensive in-situ component. Node +ve, ER +ve $(6.8 \mathrm{fm} / \mathrm{mg}$ protein), EGFR -ve $(7.8 \mathrm{fm} / \mathrm{mg}$ protein)). Case 601 (20 $\mathrm{mm} 30 \mathrm{~mm}$ tumor, grade 3 with intraductal in-situ ca. and in filtrating ductal carcinoma, node +ve, ER -ve (1.5 fm/mg protein), Her2 +ve (histoscore of 3), EGFR +ve (histoscore of 208)) was classified as ERBB2 positive based on expression microarray data with a fractional rank of 0.982 , Case 3,364 was $25 \mathrm{~mm}$ grade 3 infiltrating ductal carcinoma, ER positive $(8 \mathrm{fm} / \mathrm{mg}$ protein), PR positive (histoscore $8 / 8$ ), Her2 positive (histoscore $3+$, one of ten axillary nodes $+v e$ ). For each case, DNA was extracted from microdissected stroma and tumor, as well as the original non-dissected sample and analyzed using Illumina Human-610 Quad SNP arrays applying standard protocols.

\section{Data processing}

Genome Alteration Print was downloaded [43] and used to analyze all datasets using default settings and the highest ranked copy number and $\mathrm{LOH}$ predictions used for comparisons. However, for the cancer cell line dilution series, we re-used the results that had previously been generated by [23] and made available on the aforementioned website.

GenoCN v1.06 was downloaded [44] and used with default settings and stromal contamination settings on for all datasets generated using Illumina Infonaut II SNP arrays. Adjusted GenoCN parameters for the Log $\mathrm{R}$ Ratio levels were used for Infonaut HD SNP array processing and in these instances we used the same levels that we specified for OncoSNP. The copy number and $\mathrm{LOH}$ predictions from the Viterbi sequence were used for comparisons.

OncoSNP was run on all datasets using 15 EM iterations and with both stromal and intra-tumor heterogeneity options. In all cases, the ploidy prediction with the highest maximum likelihood was chosen and the Viterbi sequence of tumor states used for comparisons. We filtered detected aberrations using a Log Bayes Factor of 30.

\section{Statistical model}

A complete description of our statistical model is provided in Supplementary Information in Additional file 1.

Let $\boldsymbol{x}_{i}$ denote the tumor state at the $i$-th probe location and $\left(x_{i, n}, x_{i, t}\right)$ denote the associated normal and tumor copy numbers. Furthermore, let $z_{i}=\left(z_{i, n}, z_{i, t}\right)$ denote the $\mathrm{B}$ allele count for the normal and tumor genotype respectively. The combinations $\left(z_{i, n},\left(x_{i, n}\right)\right.$ and $\left(\mathrm{z}_{i, t}, x_{i, t}\right)$ fully define the normal and tumor genotypes respectively. The tumor state at each probe denotes the allowable combinations of normal-tumor genotypes at that location as shown in Table 1.

Let $\pi_{0}$ denote the normal DNA fraction of the tumor sample due to stromal contamination and $\pi=\left\{\pi_{i}\right\}_{i=1}^{n}$ denote the proportion of tumor cells having the normal genotype at each probe. The data $\boldsymbol{y}=\left\{\boldsymbol{y}_{i}\right\}_{i=1}^{n}$ consists of a set of two-dimensional vectors $\boldsymbol{y}_{i}=\left[r_{i}, b_{i}\right]^{\prime}$ whose elements correspond to the $\log \mathrm{R}$ Ratio and $\mathrm{B}$ allele frequency respectively.

Given $\left(\boldsymbol{x}, \boldsymbol{z}, \boldsymbol{\pi}, \pi_{0}\right)$ the data is assumed to be distributed according to a $(\mathrm{K}+1)$-component mixture of Student $\mathrm{t}$-distributions, where $k_{i}$ indicates the mixture component assignment of the $i$-th data point,

$$
\boldsymbol{y}_{i} \mid \boldsymbol{x}_{i}, \mathbf{z}_{i}, k_{i}, \boldsymbol{m}, \boldsymbol{\delta}, \boldsymbol{\Sigma}= \begin{cases}\operatorname{St}\left(\boldsymbol{m}\left(\boldsymbol{x}_{i}, \mathbf{z}_{i}\right)+\boldsymbol{\delta}_{k_{l}}^{\left(l_{l}\right)}, \sum_{k_{i}}^{\left(l_{i}\right)}, v\right), & k \neq 0, \\ \mathrm{U}_{r}\left(r_{\min }, r_{\max }\right) \times \mathrm{U}_{b}(0,1), & k=0,\end{cases}
$$


where $\operatorname{St}\left(\boldsymbol{\delta}_{k}^{(l)}, \Sigma_{k}^{(l)}, v\right)$ is the probability density function of the Student $t$-distribution with mean $\delta_{k}^{(l)}$ and covariance matrix $\Sigma_{k}^{(l)}$ associated with the $k$-th mixture component and the $l$-th genotype class and $v$ degrees of freedom. The 0-th component is an outlier class which assumes uniformly distributed data over a specified range.

The elements of the mean vectors $\boldsymbol{m}\left(\boldsymbol{x}_{i}, \boldsymbol{z}_{i}\right)=\left[m_{r}\left(\boldsymbol{x}_{i}\right)\right.$, $\left.m_{b}\left(\boldsymbol{z}_{i}, \boldsymbol{x}_{i}\right)\right]^{\prime}$ are given by the following:

$$
m_{r}\left(\boldsymbol{x}_{i}\right)=\left(\pi_{i}\left(1-\pi_{\mathrm{o}}\right)+\pi_{\mathrm{o}}\right) \bar{r}_{x_{i}, n}+\left(1-\pi_{i}\right)\left(1-\pi_{\mathrm{o}}\right) \bar{r}_{x_{x_{i, t}}}+\beta_{\mathrm{o}}+\beta_{1} g_{i},
$$

where $g_{i}$ is the local GC content at the $i$-th probe location and

$$
m_{b}\left(z_{i}, \boldsymbol{x}_{i}\right)=\frac{\left(\pi_{i}\left(1-\pi_{\mathrm{o}}\right)+\pi_{\mathrm{o}}\right) z_{i, n}+\left(1-\pi_{i}\right)\left(1-\pi_{\mathrm{o}}\right) z_{i, t}}{\left(\pi_{i}\left(1-\pi_{\mathrm{o}}\right)+\pi_{\mathrm{o}}\right) x_{i, n}+\left(1-\pi_{i}\right)\left(1-\pi_{\mathrm{o}}\right) x_{i, t}} .
$$

\section{Prior distributions}

The prior distribution on the mixture weights is given by a Dirichlet distribution:

$$
\boldsymbol{w}^{(l)} \mid \alpha \sim \operatorname{Dir}(\alpha)
$$

where $\alpha$ is a concentration parameter which in the numerical results we used $\alpha=1$ to give a at prior on the mixture weights.

The prior distributions on the mixture centers and covariance matrices are given by standard conjugate Normal-Inverse Wishart distributions:

$$
\begin{aligned}
& \boldsymbol{\delta}_{k}^{(l)} \mid \tau, \Sigma_{k}^{(l)} \sim \mathrm{N}\left(\mathbf{o}, \tau \Sigma_{k}^{(l)}\right), \quad k=1, \ldots, K, l=1,2,3, \\
& \Sigma_{k}^{(l)} \mid \gamma, \boldsymbol{S}_{k}^{(l)} \sim \operatorname{IW}\left(\gamma, \boldsymbol{S}_{k}^{(l)}\right), \quad k=1, \ldots, K, l=1,2,3,
\end{aligned}
$$

where $\tau$ is a hyperparameter that controls the strength of the prior and $\operatorname{IW}(\gamma, \Lambda)$ denotes the Inverse-Wishart distribution with parameter $\gamma$ and scale matrix $\Lambda$.

A beta prior is assumed for the outlier rate,

$$
\eta \mid \alpha_{\eta}, \beta_{\eta} \sim \operatorname{Be}\left(\alpha_{\eta}, \beta_{\eta}\right),
$$

where $\left(\alpha_{n}, \beta_{n}\right)$ are hyperparameters associated with the Beta prior. For the numerical results we set these as $(1,1)$ to give a uniform distribution.

A normal prior is assumed for the local GC content regression parameters,

$$
\boldsymbol{\beta} \mid \lambda_{\beta} \sim \mathrm{N}\left(\mathrm{o}, \lambda_{\beta} \boldsymbol{I}_{2}\right)
$$

where $\boldsymbol{I}_{p}$ is a $p \times p$ identity matrix.
A discrete prior is assumed for the stromal contamination content and intra-tumour heterogeneity levels,

$$
p\left(\pi_{\mathrm{o}}\right)= \begin{cases}\alpha_{\pi_{\mathrm{o}}}, & \pi_{\mathrm{o}}=\mathrm{o}, \\ \beta_{\pi_{\mathrm{o}}}, & \pi_{\mathrm{o}}>\mathrm{o}\end{cases}
$$

and

$$
p\left(\pi_{i}\right)=\left\{\begin{array}{ll}
\alpha_{\pi}, & \pi_{i}=0, \\
\beta_{\pi}, & \pi_{i}>0,
\end{array} \quad i=1, \ldots, n,\right.
$$

where in the numerical results we have used $\alpha_{\pi 0}=\beta_{\pi 0}$ $=1$ and $\alpha_{\pi}=1, \beta_{\pi}=2$.

The tumor states are assumed to form an inhomogeneous Markov Chain with transition matrix,

$$
p\left(\boldsymbol{x}_{i} \mid \boldsymbol{x}_{i-1}\right)= \begin{cases}1-\rho, & \boldsymbol{x}_{i}=\boldsymbol{x}_{i-1}, \\ \rho, & \boldsymbol{x}_{i} \neq \boldsymbol{x}_{i-1},\end{cases}
$$

where $\rho=(1 / 2)\left(1-\exp \left(-(1 / 2 L)\left(s_{i}-s_{i-1}\right)\right.\right.$ and $s_{i}$ is the physical coordinate of the $i$-th probe and $L$ is a characteristic length which we set as $L=2,000,000$ for the numerical results.

\section{Posterior inference}

We estimated the unknown model parameters using an expectation-maximization algorithm. Multiple restarts were used to explore different baseline of the Log $R$ Ratio and the baseline with the greatest likelihood was chosen for the calculation of summary statistics.

\section{Summary statistics}

We used the Viterbi algorithm to extract the most likely sequence of tumors states and for each aberrant segment in the Viterbi sequence we calculated an approximate Bayes Factor (score) of that segment belonging to each of the tumor states. In addition we also recorded the maximum a posteriori estimates of the Log R Ratio baseline adjustment $\beta_{0}$ and the stromal contamination $\pi_{0}$.

\section{Availability}

A MATLAB based implementation (for 64 bit Linux systems) of our software is available for academic and non-commercial use from the associated website [45]. In addition, SNP data analyzed in this paper are also available from this website and from the Gene Expression Omnibus Database under Accession No.[GEO: GSE23785].

\section{Additional material}

Additional file 1: Supplementary methods. Detailed description of statistical methodology. 
Additional file 2: Genome-wide analysis of three normal-cancer cell line mixtures. Plots showing genome-wide copy number and $\mathrm{LOH}$ analysis for three normal-cancer cell line mixture series.

Additional file 3: Genome-wide analysis of three primary breast tumours. Plots showing genome-wide copy number and $\mathrm{LOH}$ analysis of three primary breast tumours.

\section{Abbreviations}

aCGH: Array-based comparative genomic hybridization; BAF: B Allele Frequency; CNV: Copy number variant; LOH: Loss of heterozygosity; LRR: Log R Ratio; SNP: Single nucleotide polymorphisms.

\section{Acknowledgements}

The authors would like to thank Jean-Baptiste Cazier for general discussions and careful reading of this manuscript, Rachel Natrajan and Jorge Reis-Filho for discussion and advice on earlier versions of the work and Dan Peiffer (Illumina) for providing the cell line data for HL-60 and HT-29. CY is funded by a UK Medical Research Council Specialist Training Fellowship in Biomedical Informatics (Reference No. G0701810) and previously by a UK Engineering and Physical Sciences Research Council Life Sciences Interface Doctoral Training Studentship. JR, GM and SC were supported by a Wellcome Trust Grant 075491/Z/04/Z. DM, RJ and OS were supported by the Hilton Ludwig Cancer Metastasis Initiative. OS is supported by National Health and Medical Research Council Project Grant 489418. We also thank the reviewers for useful comments.

\section{Author details}

'Department of Statistics, University of Oxford, South Parks Road, Oxford, OX1 3TG, UK. ${ }^{2}$ Ludwig Colon Cancer Initiative Laboratory, Ludwig Institute for Cancer Research, Royal Melbourne Hospital, Victoria 3050, Australia. ${ }^{3}$ Wellcome Trust Centre for Human Genetics, University of Oxford, Roosevelt Drive, Oxford, OX3 7BN, UK. ${ }^{4}$ Molecular Oncology Laboratories, Department of Medical Oncology, University of Oxford, Weatherall institute of Molecular Medicine, Headington, Oxford OX3 9DS, UK. ${ }^{5}$ MRC Harwell, Harwell Science and Innovation Campus, Oxfordshire, OX11 ORD, UK. ${ }^{6}$ Current Address: UMR203 INRA INSA-Lyon BF2l, Biologie Fonctionnelle Insectes et Interactions, Bat. L. Pasteur, 20 ave. A. Einstein, F-69621 Villeurbanne Cedex, France.

\section{Authors' contributions}

$\mathrm{CY}, \mathrm{CCH}, \mathrm{SC}$ and JR conceived the method and generated initial ideas and discussions. CY wrote and developed the OncoSNP algorithm. DM, RJ and OS provided bioinformatics analysis and performed genotyping experiments on cancer cell lines. GM, GS, AH and JR provided tumor samples and performed genotyping experiments for the breast cancer analysis. CY, JR, OS and $\mathrm{CCH}$ wrote the paper.

\section{Received: 25 April 2010 Revised: 20 August 2010}

Accepted: 21 September 2010 Published: 21 September 2010

\section{References}

1. Beroukhim R, Getz G, Nghiemphu L, Barretina J, Hsueh T, Linhart D, Vivanco I, Lee JC, Huang JH, Alexander S, Du J, Kau T, Thomas RK, Shah K, Soto H, Perner S, Prensner J, Debiasi RM, Demichelis F, Hatton C, Rubin MA, Garraway LA, Nelson SF, Liau L, Mischel PS, Cloughesy TF, Meyerson M, Golub TA, Lander ES, Mellinghoff IK, et al: Assessing the significance of chromosomal aberrations in cancer: methodology and application to glioma. Proc Natl Acad Sci USA 2007, 104:20007-20012.

2. Weir BA, Woo MS, Getz G, Perner S, Ding L, Beroukhim R, Lin WM, Province MA, Kraja A, Johnson LA, Shah K, Sato M, Thomas RK, Barletta JA, Borecki IB, Broderick S, Chang AC, Chiang DY, Chirieac LR, Cho J, Fujii Y, Gazdar AF, Giordano T, Greulich H, Hanna M, Johnson BE, Kris MG, Lash A, Lin $L$, Lindeman $N$, et al: Characterizing the cancer genome in lung adenocarcinoma. Nature 2007, 450:893-898.

3. Caren $\mathrm{H}$, Kryh H, Nethander M, Sjoberg RM, Trager C, Nilsson S, Abrahamsson J, Kogner P, Martinsson T: High-risk neuroblastoma tumors with 11q-deletion display a poor prognostic, chromosome instability phenotype with later onset. Proc Natl Acad Sci USA 2010, 107:4323-4328.
4. Waddell N, Arnold J, Cocciardi S, da Silva L, Marsh A, Riley J, Johnstone CN, Orloff M, Assie G, Eng C, Reid L, Keith P, Yan M, Fox S, Devilee P, Godwin AK, Hogervorst FB, Couch F, Grimmond S, Flanagan JM, Khanna K, Simpson PT, Lakhani SR, Chenevix-Trench G: Subtypes of familial breast tumours revealed by expression and copy number profiling. Breast Cancer Res Treat 2010, 123:661-677.

5. Bignell GR, Greenman CD, Davies H, Butler AP, Edkins S, Andrews JM, Buck G, Chen L, Beare D, Latimer C, Widaa S, Hinton J, Fahey C, Fu B, Swamy S, Dalgliesh GL, Teh BT, Deloukas P, Yang F, Campbell PJ, Futreal PA, Stratton MR: Signatures of mutation and selection in the cancer genome. Nature 2010, 463:893-898.

6. Beroukhim R, Mermel CH, Porter D, Wei G, Raychaudhuri S, Donovan J, Barretina J, Boehm JS, Dobson J, Urashima M, Mc Henry KT, Pinchback RM, Ligon AH, Cho YJ, Haery L, Greulich H, Reich M, Winckler W, Lawrence MS, Weir BA, Tanaka KE, Chiang DY, Bass AJ, Loo A, Hoffman C, Prensner J, Liefeld T, Gao Q, Yecies D, Signoretti S, et al: The landscape of somatic copy-number alteration across human cancers. Nature 2010, 463:899-905.

7. Nannya Y, Sanada M, Nakazaki K, Hosoya N, Wang L, Hangaishi A, Kurokawa M, Chiba S, Bailey DK, Kennedy GC, Ogawa S: A robust algorithm for copy number detection using high-density oligonucleotide single nucleotide polymorphism genotyping arrays. Cancer Res 2005, 65:6071-6079.

8. Komura D, Shen F, Ishikawa S, Fitch KR, Chen W, Zhang J, Liu G, Ihara S, Nakamura H, Hurles ME, Lee C, Scherer SW, Jones KW, Shapero MH, Huang J, Aburatani H: Genome-wide detection of human copy number variations using high-density DNA oligonucleotide arrays. Genome Res 2006, 16:1575-1584.

9. Colella S, Yau C, Taylor JM, Mirza G, Butler H, Clouston P, Bassett AS, Seller A, Holmes CC, Ragoussis J: QuantiSNP: an Objective Bayes HiddenMarkov Model to detect and accurately map copy number variation using SNP genotyping data. Nucleic Acids Res 2007, 35:2013-2025.

10. Wang K, Li M, Hadley D, Liu R, Glessner J, Grant SF, Hakonarson H, Bucan M: PennCNV: an integrated hidden Markov model designed for highresolution copy number variation detection in whole-genome SNP genotyping data. Genome Res 2007, 17:1665-1674.

11. Korn JM, Kuruvilla FG, McCarroll SA, Wysoker A, Nemesh J, Cawley S, Hubbell E, Veitch J, Collins PJ, Darvishi K, Lee C, Nizzari MM, Gabriel SB, Purcell S, Daly MJ, Altshuler D: Integrated genotype calling and association analysis of SNPs, common copy number polymorphisms and rare CNVs. Nat Genet 2008, 40:1253-1260.

12. Lindblad-Toh K, Tanenbaum DM, Daly MJ, Winchester E, Lui WO, Villapakkam A, Stanton SE, Larsson C, Hudson TJ, Johnson BE, Lander ES, Meyerson M: Loss-of-heterozygosity analysis of small-cell lung carcinomas using single-nucleotide polymorphism arrays. Nat Biotechnol 2000, 18:1001-1005.

13. Zhao X, Li C, Paez JG, Chin K, Janne PA, Chen TH, Girard L, Minna J, Christiani D, Leo C, Gray JW, Sellers WR, Meyerson M: An integrated view of copy number and allelic alterations in the cancer genome using single nucleotide polymorphism arrays. Cancer Res 2004, 64:3060-3071.

14. LaFramboise T, Weir BA, Zhao X, Beroukhim R, Li C, Harrington D, Sellers WR, Meyerson M: Allele-specific amplification in cancer revealed by SNP array analysis. PLoS Comput Biol 2005, 1:e65.

15. Diskin SJ, Li M, Hou C, Yang S, Glessner J, Hakonarson H, Bucan M, Maris JM, Wang K: Adjustment of genomic waves in signal intensities from whole-genome SNP genotyping platforms. Nucleic Acids Res 2008, 36:e126.

16. Peiffer DA, Le JM, Steemers FJ, Chang W, Jenniges T, Garcia F, Haden K, Li J, Shaw CA, Belmont J, Cheung SW, Shen RM, Barker DL, Gunderson KL: Highresolution genomic profiling of chromosomal aberrations using Infinium whole-genome genotyping. Genome Res 2006, 16:1136-1148.

17. Attiyeh EF, Diskin SJ, Attiyeh MA, Mosse YP, Hou C, Jackson EM, Kim C, Glessner J, Hakonarson H, Biegel JA, Maris JM: Genomic copy number determination in cancer cells from single nucleotide polymorphism microarrays based on quantitative genotyping corrected for aneuploidy. Genome Res 2009, 19:276-283.

18. Bengtsson H, Irizarry R, Carvalho B, Speed TP: Estimation and assessment of raw copy numbers at the single locus level. Bioinformatics 2008, 24:759-767.

19. Bengtsson $H$, Neuvial P, Speed TP: TumorBoost: normalization of allelespecific tumor copy numbers from a single pair of tumor-normal genotyping microarrays. BMC Bioinformatics 2010, 11:245. 
20. Goransson H, Edlund K, Rydaker M, Rasmussen M, Winquist J, Ekman S, Bergqvist $M$, Thomas $A$, Lambe $M$, Rosenquist $R$, Holmberg $L$, Micke $P$, Botling J, Isaksson A: Quantification of normal cell fraction and copy number neutral LOH in clinical lung cancer samples using SNP array data. PLoS One 2009, 4:e6057.

21. Greenman CD, Bignell G, Butler A, Edkins S, Hinton J, Beare D, Swamy S, Santarius T, Chen L, Widaa S, Futreal PA, Stratton MR: PICNIC: an algorithm to predict absolute allelic copy number variation with microarray cancer data. Biostatistics 2010, 11:164-175.

22. Lamy P, Andersen CL, Dyrskjot L, Torring N, Wiuf C: A Hidden Markov Model to estimate population mixture and allelic copy-numbers in cancers using Affymetrix SNP arrays. BMC Bioinformatics 2007, 8:434.

23. Popova T, Manie E, Stoppa-Lyonnet D, Rigaill G, Barillot E, Stern MH: Genome Alteration Print (GAP): a tool to visualize and mine complex cancer genomic profiles obtained by SNP arrays. Genome Biol 2009, 10: R128.

24. Staaf J, Lindgren D, Vallon-Christersson J, Isaksson A, Goransson H, Juliusson G, Rosenquist R, Hoglund M, Borg A, Ringner M: Segmentationbased detection of allelic imbalance and loss-of-heterozygosity in cancer cells using whole genome SNP arrays. Genome Biol 2008, 9:R136.

25. Sun W, Wright FA, Tang Z, Nordgard SH, Van Loo P, Yu T, Kristensen VN, Perou CM: Integrated study of copy number states and genotype calls using high-density SNP arrays. Nucleic Acids Res 2009, 37:5365-5377.

26. Wang K, Li J, Li S, Bolund L, Wiuf C: Estimation of tumor heterogeneity using CGH array data. BMC Bioinformatics 2009, 10:12.

27. Yamamoto $G$, Nannya $Y$, Kato M, Sanada M, Levine RL, Kawamata N, Hangaishi A, Kurokawa M, Chiba S, Gilliland DG, Koeffler HP, Ogawa S: Highly sensitive method for genomewide detection of allelic composition in nonpaired, primary tumor specimens by use of affymetrix single-nucleotide-polymorphism genotyping microarrays. Am $J$ Hum Genet 2007, 81:114-126.

28. Yau C, Holmes CC: CNV discovery using SNP genotyping arrays. Cytogenet Genome Res 2008, 123:307-312.

29. LaFramboise T: Single nucleotide polymorphism arrays: a decade of biological, computational and technological advances. Nucleic Acids Res 2009, 37:4181-4193.

30. Ragoussis J: Genotyping technologies for genetic research. Annu Rev Genomics Hum Genet 2009, 10:117-133.

31. Winchester $L$, Yau C, Ragoussis J: Comparing CNV detection methods for SNP arrays. Brief Funct Genomic Proteomic 2009, 8:353-366.

32. Pfeifer D, Pantic M, Skatulla I, Rawluk J, Kreutz C, Martens UM, Fisch P, Timmer J, Veelken $\mathrm{H}$ : Genome-wide analysis of DNA copy number changes and LOH in CLL using high-density SNP arrays. Blood 2007 109:1202-1210.

33. Staaf J, Vallon-Christersson J, Lindgren D, Juliusson G, Rosenquist R, Hoglund M, Borg A, Ringner M: Normalization of Illumina Infinium wholegenome SNP data improves copy number estimates and allelic intensity ratios. BMC Bioinformatics 2008, 9:409.

34. Gardina PJ, Lo KC, Lee W, Cowell JK, Turpaz Y: Ploidy status and copy number aberrations in primary glioblastomas defined by integrated analysis of allelic ratios, signal ratios and loss of heterozygosity using 500K SNP Mapping Arrays. BMC Genomics 2008, 9:489.

35. Marioni JC, Thorne NP, Valsesia A, Fitzgerald T, Redon R, Fiegler $H_{\text {, }}$ Andrews TD, Stranger BE, Lynch AG, Dermitzakis ET, Carter NP, Tavare S, Hurles ME: Breaking the waves: improved detection of copy number variation from microarray-based comparative genomic hybridization. Genome Biol 2007, 8:R228.

36. Abdel-Rahman WM, Katsura K, Rens W, Gorman PA, Sheer D, Bicknell D, Bodmer WF, Arends MJ, Wyllie AH, Edwards PA: Spectral karyotyping suggests additional subsets of colorectal cancers characterized by pattern of chromosome rearrangement. Proc Natl Acad Sci USA 2001, 98:2538-2543.

37. Liang JC, Ning Y, Wang RY, Padilla-Nash HM, Schrock E, Soenksen D, Nagarajan L, Ried T: Spectral karyotypic study of the HL-60 cell line: detection of complex rearrangements involving chromosomes 5, 7, and 16 and delineation of critical region of deletion on $5 q 31.1$. Cancer Genet Cytogenet 1999, 113:105-109.

38. Rowan A, Halford S, Gaasenbeek M, Kemp Z, Sieber O, Volikos E, Douglas E, Fiegler H, Carter N, Talbot I, Silver A, Tomlinson I: Refining molecular analysis in the pathways of colorectal carcinogenesis. Clin Gastroenterol Hepatol 2005, 3:1115-1123.
39. Chiang DY, Getz G, Jaffe DB, O'Kelly MJ, Zhao X, Carter SL, Russ C, Nusbaum C, Meyerson M, Lander ES: High-resolution mapping of copynumber alterations with massively parallel sequencing. Nat Methods 2009, 6:99-103.

40. Pleasance ED, Stephens PJ, O'Meara S, McBride DJ, Meynert A, Jones D, Lin ML, Beare D, Lau KW, Greenman C, Varela I, Nik-Zainal S, Davies HR, Ordonez GR, Mudie LJ, Latimer C, Edkins S, Stebbings L, Chen L, Jia M, Leroy C, Marshall J, Menzies A, Butler A, Teague JW, Mangion J, Sun YA, McLaughlin SF, Peckham HE, Tsung EF, et al: A small-cell lung cancer genome with complex signatures of tobacco exposure. Nature 2010, 463:184-190.

41. Stephens PJ, McBride DJ, Lin ML, Varela I, Pleasance ED, Simpson JT, Stebbings LA, Leroy C, Edkins S, Mudie LJ, Greenman CD, Jia M, Latimer C, Teague JW, Lau KW, Burton J, Quail MA, Swerdlow H, Churcher C, Natrajan R, Sieuwerts AM, Martens JW, Silver DP, Langerod A, Russnes HE, Foekens JA, Reis-Filho JS, van't Veer L, Richardson AL, Borresen-Dale AL, et al: Complex landscapes of somatic rearrangement in human breast cancer genomes. Nature 2009, 462:1005-1010.

42. Ding L, Ellis MJ, Li S, Larson DE, Chen K, Wallis JW, Harris CC, McLellan MD, Fulton RS, Fulton LL, Abbott RM, Hoog J, Dooling DJ, Koboldt DC, Schmidt H, Kalicki J, Zhang Q, Chen L, Lin L, Wendl MC, McMichael JF, Magrini VJ, Cook L, McGrath SD, Vickery TL, Appelbaum E, Deschryver K, Davies $S$, Guintoli T, Lin $L$, et al: Genome remodelling in a basal-like breast cancer metastasis and xenograft. Nature 2010, 464:999-1005.

43. GAP.. [http://bioinfo-out.curie.fr/projects/snp_gap/]

44. GenoCN.. [http://www.bios.unc.edu/ wsun/software/genoCN.htm].

45. OncoSNP.. [https://sites.google.com/site/oncosnp/].

\section{doi:10.1186/gb-2010-11-9-r92}

Cite this article as: Yau et al.: A statistical approach for detecting genomic aberrations in heterogeneous tumor samples from single nucleotide polymorphism genotyping data. Genome Biology 2010 11:R92.

\section{Submit your next manuscript to BioMed Central and take full advantage of:}

- Convenient online submission

- Thorough peer review

- No space constraints or color figure charges

- Immediate publication on acceptance

- Inclusion in PubMed, CAS, Scopus and Google Scholar

- Research which is freely available for redistribution

Submit your manuscript at www.biomedcentral.com/submit
C Biomed Central 